\title{
Physician compliance and market demographics
}

Received (in revised form): 30th October, 2006

\section{Lynne Tudhope}

is a vascular surgeon in private practice in Pretoria, South Africa, where she is also a consultant in surgery to the university. She specialises in the insertion of arterial stents, and runs a diabetic foot clinic. She has presented many papers at academic conferences, and published in medical journals.

\section{Melani Prinsloo}

is a PhD candidate at the Lulea University of Technology, Sweden. She is a director of Gluemetric, a marketing research company in Pretoria, South Africa, and she also teaches marketing as an adjunct member of faculty at Ecole Nationale Ponts et Chaussees, Paris, France. Her work has appeared in journals such as Advertising Express and International Journal of Technology Marketing.

\section{Leyland Pitt}

is Professor of Marketing at the Segal Graduate School of Business, Simon Fraser University, Vancouver, Canada. His work has been published in The Journal of Advertising Research, The Journal of Advertising, Information Systems Research, Journal of the Academy of Marketing Science, Sloan Management Review, Business Horizons, California Management Review, Communications of the ACM and MIS Quarterly (which he also served as Associate Editor), and in 2000 he was the recipient of the Tamer Cavusgil Award of the American Marketing Association for the best article in the Journal of International Marketing.

\section{Bradley R. Barnes}

is Senior Lecturer in Marketing at Leeds University Business School. He initially studied for his undergraduate degree at Sheffield Business School, before completing his Masters in Marketing at the University of Huddersfield, and PhD from the University of Leeds. Bradley has published in a number of academic and practitioner-led Journals, including Industrial Marketing Management, European Journal of Marketing, Journal of Medical Marketing and Journal of Business-to-Business Marketing, among others.

\section{Keywords demographic marketing, physician compliance, South Africa}

Abstract The notion of patient compliance is a significant topic of debate, as by nature it has implications on a broad community of stakeholders including pharmaceutical manufacturers, physicians who prescribe drugs, patients who may or may not decide to comply, as well as national governments that operate under budgetary constraints. Based on data collected from 2921 South Africa respondents, it would appear that in order to increase sample compliance, the various stakeholders in South Africa may need to undertake further research with the male population, young patients, the relatively more educated and middle income groups, as these sub-categories of individuals have less of a tendency to comply with their physicians' instructions when taking drugs. Journal of Medical Marketing (2007) 7, 64-70. doi:10.1057/palgrave.jmm.5050067

\section{INTRODUCTION: COMPLIANCE AND MARKETING}

Compliance with a physician's instructions, 'doing what the doctor says' is important for a number of reasons. First, it is in a patient's best interests to comply if they are either to return to a state of health or maintain a good one. Secondly, it is fundamental to a good physician-patient relationship that the latter conform to the former's instructions and requests. Thirdly, it is in many cases in society's best interests that there is compliance with physician instructions. One of the 
main reasons for the development of antibiotic-resistant strains of super-bacteria is that patients only continue taking medication until they feel better, not for the duration that a physician has mandated.

Compliance has frequently been regarded as a marketing issue for healthcare authorities, who wish to ensure that patients receive optimal care; for pharmaceutical firms, who are concerned that consumers who are prescribed their products consume them as intended; and for physicians who see it as an important mechanism in the healing cycle, and because they have the best interests of the patient in mind, view it as the way in which patients will achieve the best results. Compliance is a marketing issue from two perspectives: From the provider-physician's perspective, the essential concern is in determining what the characteristics are of those physicians who are more successful in obtaining compliance, and what the strategies are that they use to achieve this.

From a patient or customer perspective, there is an interest in the characteristics of those individuals who exhibit either low or high tendencies to comply. In simple terms, it is a market segmentation and targeting issue. If we know the characteristics of patients with a lower propensity to comply, it is easier to focus marketing effort on them in an attempt to motivate them to conform. These characteristics may be behavioural, and could be related to aspects of personality and attitude. Alternatively, such characteristics may simply be demographic. It is possible that compliance is a function of fundamental demographic characteristics such as age, level of education, gender and so forth.

By focusing on such characteristics, it is considered that this research will add to our understanding of the area, and provide useful insights for managerial practitioners, such as pharmaceutical suppliers, as well as physicians that are often grappling with these fundamental issues. In addition, it is also believed that the findings may prove to be of further interest for academicians who are actively engaged in research within medical markets. This paper presents the results from a large demographic study of compliance, based on data obtained from South African townships. It is structured as follows: First, some of the literature with specific reference to compliance as a marketing and consumer behaviour issue is reviewed. Secondly, the subject of compliance issues is outlined, as well as the research objectives and methodology. Thirdly, the results of the study are discussed and the paper concludes by identifying the study's limitations and its practical implications, before identifying avenues for future research.

\section{BACKGROUND}

\section{Compliance - The marketing perspective}

In noting that the actual performance of drugs in real-world clinical settings seldom approach those outcomes attained in controlled trials, Lindström and Bingefors ${ }^{1}$ note a number of factors that can influence compliance. These include drug type and formulation, the patient, the status of the disease, the physician's characteristics, the type of healthcare system and the role of community care and family. As long ago as 1976, Komaroff ${ }^{2}$ observed that research in the previous 20 years had provided a sophisticated understanding of what goes on when medication is prescribed. He noted, however, investigations of patient drug-taking behaviour indicated that an unsuccessful outcome may not reflect on the potency of the medication, or the biology of the patient; rather, the drug may not have been taken as prescribed.

Various methodologies had been used to study patient compliance, ranging from 
simple pill counts to the use of medication dispensers using radioactive material and photographic film to record the regularity with which medication packets were removed. Many factors can influence patient drug-taking behaviour, factors which are reflections of the patient, the practitioner and the patient-practitioner relationship. More recent research has demonstrated the very real concerns that physicians have about their patients' unwillingness to comply. For example, Daugherty et al. ${ }^{3}$ surveyed 31 physicians who perceived that between one-third and two-thirds of patients do not comply with instructions, and that nearly one-third of those who comply do not show optimal treatment response. The physicians expressed concerns about the validity and cost of complementary approaches that might increase medical compliance and enhance treatment response.

One of the earliest and still most important studies of physician compliance was the work of Friedman and Churchill, ${ }^{4}$ who considered the implications of personal influence research on the effectiveness of physician-patient encounters. A significant contribution of the study was the development of a short, psychometrically sound instrument to measure physician compliance. More recently, Hausman ${ }^{5}$ has argued that physician-patient service encounters may be different from other service marketing experiences in that they involve (1) oneon-one interactions, (2) frequent encounters with the same physician, (3) intimate exchanges, (4) substantial variability across encounters and (5) require patient cooperation to achieve successful health outcomes.

Just as the early work previously discussed, she argues that this type of encounter increases patient reliance on interpersonal elements to drive satisfaction. Indeed, she contends, it is these interpersonal elements of the physician- patient interface that will encourage compliance with medical advice. The results of her study sustain the contention that interactions among these variables contribute to patient satisfaction and compliance. She also found support for the role of interpersonal interactions in loyalty and recommendation, although these relationships were found to vary depending on sample characteristics.

While physician compliance has been the subject of many studies in the medical, psychological and social marketing literatures, less attention, however, seems to have been paid to the demographics of compliance. While the focus has deservedly been on issues such as patient-physician relationships, physician behaviour and communication and the patient psychology of compliance, there is less attention given to simple questions such as, do females comply more than males (or vice versa), do better educated individuals comply more than less educated, do the wealthy comply more than the poor and does age make a difference? This paper attempts to bridge a gap in the literature, by looking to provide further insights in such areas.

\section{The research approach}

The objectives of the study were to initially describe compliance demographics in large South African townships, and secondly, to be able to predict the likelihood of compliance in a large population based on simple demographic variables. The study was conducted as part of a larger scale examination on various aspects of consumption for inhabitants of all South Africa's major townships, including KwaMashu, Tembisa, Soshanguve, Mamelodi, Khayelitsha, Manguang, Soweto and Vaalbank. In total, 3,500 personal interviews were conducted on adult respondents, spread more or less equally over the eight townships.

South Africa's large townships represent an intriguing mix of emerging and 
developed worlds. They are populated largely by black Africans who have begun to emerge from the ravages of the apartheid system in the past ten years or so. Unlike their counterparts in informal squatter settlements, many township dwellers are employed, reasonably well educated and live above a nominal poverty line. Compared to the majority of their white compatriots, however, township dwellers are still at an economic disadvantage, in terms of income, education and general standard of living, although this gap has closed markedly in recent years. The demographic variables of concern for this investigation included gender, age, level of education, size of household, marital status and monthly household income.

For this investigation, a simplified version of the Physician Compliance questionnaire ${ }^{4}$ was used, consisting of five items scored on a four-point scale (always, often, seldom, never), and a sixth item assessing overall willingness to comply ('Overall, do you do what your doctor instructs or asks you to do?'), also scored on a four-point scale (always, often, seldom, never). The 3,500 questionnaires were subjected to rigorous quality control and any incomplete questionnaires were excluded from the analysis. As a result, 2,921 fully completed questionnaires were used at the data analysis stage. This represents a very large sample size and exceeds most other demographic studies of healthcare behaviour.

\section{DATA ANALYSIS AND RESULTS}

Demographics of the study group are shown in Table 1.

\section{Physician compliance}

The mean responses and standard deviations, to the five items from the Friedman and Churchill ${ }^{4}$ physician
Table 1: Demographics of study group

\begin{tabular}{|c|c|}
\hline & $\%$ \\
\hline \multicolumn{2}{|l|}{ Gender } \\
\hline Male & 41.8 \\
\hline Female & 58.2 \\
\hline \multicolumn{2}{|l|}{ Age (years) } \\
\hline$<20$ & 4.1 \\
\hline $20-24$ & 19.0 \\
\hline $25-34$ & 45.7 \\
\hline $35-49$ & 27.2 \\
\hline$>50$ & 7.6 \\
\hline \multicolumn{2}{|l|}{ Education } \\
\hline High school not completed & 24.0 \\
\hline High school completed & 48.8 \\
\hline Post high school qualification & 27.2 \\
\hline \multicolumn{2}{|l|}{ Number of people in household } \\
\hline $1-2$ & 13.5 \\
\hline $3-4$ & 26.1 \\
\hline $5-6$ & 36.7 \\
\hline 7 or more & 13.7 \\
\hline \multicolumn{2}{|l|}{ Marital status } \\
\hline Single & 61.4 \\
\hline Married/living with partner & 33.0 \\
\hline Divorced & 3.1 \\
\hline Widowed & 2.6 \\
\hline \multicolumn{2}{|c|}{ Income/month (1 South Africa Rand $=\sim £ 0.07 / \$ 0.13$ ) } \\
\hline$<R 1,400(\sim £ 98 / \$ 184)$ & 16.3 \\
\hline $\begin{array}{l}\text { R1400-R2499 ( £98/\$184 to } \\
£ 175 / \$ 328)\end{array}$ & 24.9 \\
\hline R2500-R4999 ( £175/\$328 to & 32.0 \\
\hline$£ 350 / \$ 655)$ & \\
\hline $\begin{array}{l}\text { R5000-R8000 ( £350/\$655 to } \\
£ 560 / \$ 1048)\end{array}$ & 19.7 \\
\hline$>\operatorname{R5000}(\sim £ 560 / \$ 1,048)$ & 7.1 \\
\hline
\end{tabular}

compliance scale are shown in Table 2. The Cronbach Alpha (the reliability coefficient) for the scale was 0.56 and while this is below the generally accepted cut-off of 0.7 , it is in congruence with the performance of the scale in the original research, which found an alpha of 0.55 .

In order to determine the dimensionality of the scale, we subjected the data to a principal components factor analysis, with varimax rotation, using the eigenvalues $>1$ criterion. The results of this procedure are shown in Table 3. Items 2, 3 and 4 load strongly on factor 1 ; because these items all have to do with following the physician's orders, this factor 
Table 2: Physician compliance (four-point scale 1=Always, 4=Never)

\begin{tabular}{lll}
\hline Item & Mean & Standard Dev \\
\hline $\begin{array}{l}\text { If this doctor told you something, would you visit another doctor and see what } \\
\text { they said (to get a second opinion) before actually doing it? }\end{array}$ & 2.56 & 1.26 \\
$\begin{array}{l}\text { If your doctor told you to change something (like to stop smoking, drink less } \\
\text { alcohol or loose some weight), would you do what the doctor said? }\end{array}$ & 1.63 & 0.86 \\
$\begin{array}{l}\text { If the doctor asks you to come back in a week, would you go back if you are } \\
\quad \text { feeling better? }\end{array}$ & 1.92 & 1.08 \\
$\begin{array}{l}\text { Do you always completely follow the doctor's instructions (such as taking your } \\
\text { medicine until it is finished)? }\end{array}$ & 1.73 & 0.91 \\
$\begin{array}{l}\text { Do you tell the doctor that you are drinking the medicine/changing your behav- } \\
\text { iour even if you are not (to stay out of trouble)? }\end{array}$ & 2.71 & 1.24 \\
\begin{tabular}{l} 
Overall, do you do what your doctor instructs or asks you to do? \\
\hline
\end{tabular}
\end{tabular}

Coefficient Alpha for items 1 to 5: 0.56 .

Table 3: Factor analysis rotated components, physician compliance scale

\begin{tabular}{|c|c|c|c|}
\hline & Items & Factor 1 & Factor 2 \\
\hline 1. & $\begin{array}{l}\text { If this doctor told you something, would you visit another doctor and } \\
\text { see what they said (to get a second opinion) before actually doing } \\
\text { it? }\end{array}$ & 0.205068 & 0.712904 \\
\hline 2. & $\begin{array}{l}\text { If your doctor told you to change something (like to stop smoking, } \\
\text { drink less alcohol or loose some weight), would you do what the } \\
\text { doctor said? }\end{array}$ & 0.786536 & -0.098663 \\
\hline 3. & $\begin{array}{l}\text { If the doctor asks you to come back in a week, would you go back } \\
\text { if you are feeling better? }\end{array}$ & 0.778943 & 0.264143 \\
\hline 4. & $\begin{array}{l}\text { Do you always completely follow the doctor's instructions (such as } \\
\text { taking your medicine until it is finished)? }\end{array}$ & 0.789861 & 0.076235 \\
\hline 5. & $\begin{array}{l}\text { Do you tell the doctor that you are drinking the medicine/changing } \\
\text { your behaviour even if you are not (to stay out of trouble)? }\end{array}$ & -0.079235 & 0.842754 \\
\hline
\end{tabular}

was named as 'Conforming'. Items 1 and 5 load strongly on factor 2 , and have to do with mistrusting the physician, as a result, this factor was labelled 'Doubt'. As a consequence of the analysis, it can be seen that physician compliance appears not to be a unidimensional construct, or at least not for the respondents in this study.

In order to at least establish a basic indication of the convergent validity of the construct, as well as to determine whether one could work with a simpler overall indication of physician compliance, multivariate regression analysis was undertaken, using the two factors as predictors of the overall measure of physician compliance (see Item 6 in Table 2 - Overall, do you do what your doctor instructs or asks you to do?). Not surprisingly, the two factors are strongly correlated with overall compliance. With an $R^{2}$ of 0.332 , the impact of each of the factors is significant at $p<0.001$. This provides evidence of the convergent validity of the physician compliance scale. It also provides support for using the overall rating of compliance as a measure of a patient's willingness to comply with a physician's instructions.

\section{Gender}

Females demonstrated slightly higher compliance to a physician's instructions than males. While the $R^{2}$ was very small (0.002), the $F$ ratio of 6.12 was significant at $p<0.05$.

\section{Age demographics}

There was a small but significant $\left(R^{2}\right.$ of 0.01 ; $F$ ratio: $8.48, p<0.001)$ difference 
between the age groups, which showed that the older a subject, the more likely they were to comply with their physicians' instructions.

\section{Education}

There was a small but significant $\left(R^{2}\right.$ of 0.012; $F$ ratio: $18.35, p<0.001)$ difference between the groups which showed that more educated respondents were less likely to comply with a physician's instructions.

\section{Marital status}

Although the outcomes of the ANOVAs were more complex than in previous examples, there was still a small but significant difference between the groups $\left(R^{2}=0.003 ; F\right.$ ratio: $\left.2.85, p<0.05\right)$ which showed that widowed respondents were more likely to comply than the other groups.

\section{Income levels}

The results of this analysis can be represented by an inverted $U$ whereby the highest and lowest income groups appear more likely to comply than middle income groups $\left(R^{2}=0.01 ; F\right.$ ratio: 8.94, $p<0.001)$.

\section{Household size}

With a low $R^{2}$ of 0.01 , the ANOVA $F$ ratio of 5.28 was significant at $p<0.001$ and showed that only the large households (with seven or more inhabitants) were significantly different from the rest, and in this case were more likely to comply with physician instructions.

\section{DISCUSSION, IMPLICATIONS AND CONCLUSION}

Through focusing on demographic characteristics, it is believed that the research has been able to present specific findings that may prove interesting to the medical and healthcare sector at large. The notion of patient compliance is a significant topic of debate, as by nature it has implications to a broad community of stake holders including pharmaceutical manufacturers, doctors and physicians that prescribe drugs, patients who may, or may not decide to comply, as well as national governments that operate under budgetary constraints.

Based on the findings presented, six key observations can be gleaned that are worthy of being highlighted at this stage, as they may present hypotheses or avenues that prove useful for further researchers to consider when grappling with demographic issues in medical markets: (1) females tend to demonstrate greater compliance than males, (2) younger patients are less likely to comply than the relatively older, (3) the more educated are less likely to comply than the less educated, (4) marital status does significantly influence compliance, but widowers are more likely to comply, (5) high- and low-income groups are more likely to comply, than middleincome groups and (6) large households (with seven or more) have a greater tendency to comply than other groupings.

In response, it would appear that in order to increase compliance, pharmaceutical firms, the South African government and physicians may need to collectively target and work specifically with those members of society that have a less tendency to comply. Initially it would appear that the following four categories would represent ideal segments that could be targeted in a bid to increase compliance: Members of the male population, young patients, the relatively more educated, as well as the middleincome groups. And in order to successfully implement such action (which also relates to one of the study's limitations), there is, however, a need for qualitative research. Although statistically, there is evidence to suggest of variations associated with demographics, further research is needed here to explain 'how' 
and 'why' such significant differences occur. By attempting to tackle such issues, perhaps via focus group discussions or further personal interviews, it may be possible to draw further insights relating to different customer attitudes and values among the various sub-group demographics. The results may help to provide clues as to some of the underlying issues that drive such resistance to compliance and help pharmaceutical organisations and physicians provide more effective solutions when trying to promote and encourage patients to comply.

The researchers acknowledge that this investigation was not intended to provide findings of a general nature. Practitioners are encouraged to consider the results, yet keep an open mind. As outlined, the results are very specific to certain subsegments of the South African population, and should not be applied out of context. Instead, further research of a similar nature that takes into account demographic attributes in other countries is urged. It would prove interesting to compare less developed nations, with developing and highly developed economies to see if significant differences emerge across countries. Such findings would provide interesting insights for pharmaceutical companies, physicians and national governments as they continue to grapple with issues associated with patient compliance. Can lessons learnt in one country be transferred to others? Such issues are also likely to provide stimulating debate for academics too who share an interest in medical markets.

\section{References}

1 Lindström, E. \& Bingefors, K. (2000). Patient compliance with drug therapy in schizophrenia: economic and clinical Issues. PharmacoEconomics 18(2), 105-124.

2 Komaroff, A. L. (1976). The practitioner and the compliant patient. Am. J. Pub. Health 66(9), 833-835.

3 Daugherty, T., Sherenco, K., Davis, H. \& McClelland, M. (2003). Physicians' perceptions of compliance and attitudes toward complementary care. Psychol. Rep. 93(2), 479-480.

4 Friedman, M. L. \& Churchill Jr., G. A. (1987). Using consumer perceptions and a contingency approach to improve healthcare delivery. J. Consum. Res. 13(4), 492-511.

5 Hausman, A. (2004). Modeling the patient-physician service encounter: improving patient outcomes. J. Acad. Market. Sci. 32(4), 403-417. 